pregnant women with high titre syphilis. Although syphilis screening and treatment is a national policy and is one of the most cost effective interventions, its implementation on a large scale is limited. Lack of a simple and rapid point of care diagnostic test for syphilis has been suggested as one of the major reasons for this limitation. We implemented a demonstration project in Geita district, Tanzania to assess the feasibility of introducing a rapid diagnostic test in antenatal care services. The objectives of the project were to determine (1) the feasibility of increasing access to antenatal syphilis screening using same day testing and treatment strategy, and (2) the acceptability of introducing rapid syphilis testing to service providers and clients.

Methods A health facility based baseline survey was carried out using a structured questionnaire to determine syphilis uptake before rapid test introduction. A team of four district trainers and supervisors were trained on how to perform the test, on quality assurance and stock management. Health workers were also trained on how to perform the test, quality assurance and stock management. Then rapid tests were introduced in all health facilities and qualitative data were collected to assess acceptability of the test. The uptake of syphilis testing and treatment among pregnant women in 3 months before and after rapid test introduction were compared using $\chi^{2}$ test. Results Numbers of pregnant women tested in the 3 months after rapid test introduction were significantly higher than those tested before its introduction in the same period $(p<0.01)$. Similarly a significantly higher number of syphilis positive women were treated compared to those treated before test introduction $(\mathrm{p}<0.01)$ see Abstract S2.1 figure 1. The same day testing and treatment strategy enabled $95 \%$ of women testing positive to be treated at their first visit. The rapid test was acceptable to both service providers and clients. Conclusions Introduction of rapid syphilis tests has made it possible to implement national policy for screening pregnant women in Tanzania. Increasing access to screening and treatment will prevent many perinatal deaths.

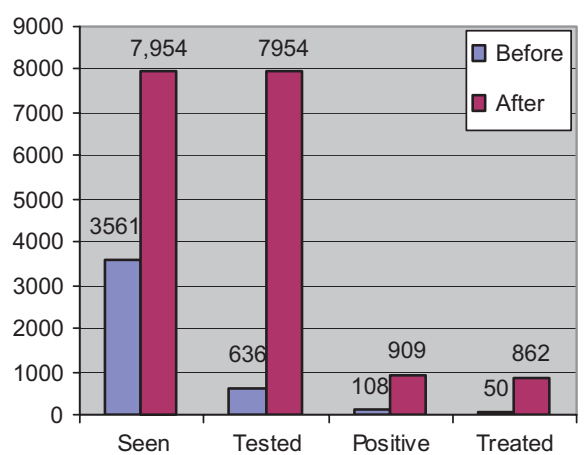

Abstract S2.1 Figure 1 Number of pregnant women tested and treated at clinics before and after Rapid Test introduction in 3 months.

\section{S2.2 INCREASING ACCESS TO HIV AND SYPHILIS SCREENING IN REMOTE AREAS USING RAPID TESTS}

doi:10.1136/sextrans-2011-050102.6

${ }^{1}$ A Benzaken, ${ }^{2}$ V M Pinto, ${ }^{3} \mathrm{C}$ H Carvalho, ${ }^{4} \mathrm{R}$ Peeling. ${ }^{1}$ Fundacao Alfredo da Matta Manaus, Brasil; ${ }^{2}$ Secretaria de Saúde de São Paulo, São Paulo, Brasil; ${ }^{3}$ Fundação Alfredo da Matta, Manaus, Brasil; ${ }^{4}$ London School of Hygiene \& Tropical Medicine, London, UK

Background Syphilis continues to be a public health problem in Brazil, particularly among populations with limited access to health services. Indigenous populations, who live in remote locations in the interior of the Amazon forest, are of even greater concern. Traditional laboratory tests for the diagnosis of syphilis are scarce in these regions. The objective of this presentation is to describe the implementation of rapid tests (RT) in the Amazon region.

Methods We trained health professionals of 9 Special Indigenous Health Districts (DSEI) to screen the sexually active population (over 10 years of age) for syphilis and HIV using RT with Quality Assurance (OA).

Results In total, 509 health professionals were trained and 160 units participated in the screening efforts. From a sexually active population of 83311 indigenous people 38799 (47\%) were tested, of whom $594(1.5 \%)$ tested positive for syphilis. 44/3650 pregnant women $(1.3 \%)$ tested positive for syphilis, and 3 for HIV $(0.1 \%)$. There is extensive variation between the rate of syphilis and HIV positivity between DSEIs (Abstract S2.2 table 1). The external OA performance was important in assuring correct results as initial scores were $77.1 \%$ for the HIV test and $61.5 \%$ for the syphilis test.

Conclusions This project has demonstrated to policy makers in Brazil the existence of syphilis and HIV among indigenous people and the feasibility of addressing it. As a result of this work, it is now government policy to use RT to screen for HIV and syphilis with OA in remote regions of Brazil. This project provided a model for the introduction of point of care tests supported by a OA programme in remote regions.

\section{S2.3 SCREENING HIGH-RISK POPULATIONS USING RAPID SYPHILIS TESTS: THE IMPORTANCE OF SOCIAL AND CULTURAL CONTEXTS}

doi:10.1136/sextrans-2011-050102.7

${ }^{1} \mathrm{X}$ S Chen, ${ }^{1} Y \mathrm{P}$ Yin, ${ }^{1} \mathrm{~W}$ H Wei, ${ }^{2} \mathrm{R}$ Peeling. ${ }^{1}$ National Center for STD Control, China CDC, Nanjing, China; ${ }^{2}$ London School of Hygiene \& Tropical Medicine, London, UK

Background Syphilis has made a dramatic resurgence in China during the past 2 decades with an increasing prevalence in high-risk groups. Screening of syphilis in the populations is critical for control of the disease.

Abstract S2.2 Table 1 Syphilis and HIV screening progress

\begin{tabular}{|c|c|c|c|c|c|}
\hline DSEI & $\begin{array}{l}\text { \# Screened / sexually } \\
\text { active population (\%) }\end{array}$ & $\begin{array}{l}\text { Syphilis prevalence in } \\
\text { sexually active population }\end{array}$ & $\begin{array}{l}\text { HIV prevalence in sexually } \\
\text { active population }\end{array}$ & $\begin{array}{l}\text { Syphilis prevalence } \\
\text { in pregnant women }\end{array}$ & $\begin{array}{l}\text { HIV prevalence in } \\
\text { pregnant women }\end{array}$ \\
\hline Manaus & $5.957 / 10.980(54.2 \%)$ & $1.51 \%$ & $0.08 \%$ & $3 / 327(0.93 \%)$ & $0 / 323(0.0 \%)$ \\
\hline Yanomani & $1.757 / 4.317(40.7 \%)$ & $0.06 \%$ & $0.17 \%$ & $1 / 284(0.35 \%)$ & $2 / 284(0.70 \%)$ \\
\hline Leste roraima & $2.666 / 4.038(66.0 \%)$ & $0.41 \%$ & $0.08 \%$ & $2 / 567(0.40 \%)$ & $0 / 472(0.0 \%)$ \\
\hline Alto solimões & $19.147 / 25.322(75.6 \%)$ & $1.90 \%$ & $0.13 \%$ & $30 / 1.412(2.27 \%)$ & $0 / 1.272(0.0 \%)$ \\
\hline Parintins & $2.324 / 4.904(47.4 \%)$ & $0.34 \%$ & $0.04 \%$ & $1 / 254(0.39 \%)$ & $0 / 253(0.0 \%)$ \\
\hline Alto rio Negro & $4.892 / 19.872(24.6 \%)$ & $0.72 \%$ & $0.08 \%$ & $4 / 639(0.72 \%)$ & $0 / 561(0.0 \%)$ \\
\hline Médio solimões & $580 / 9.092(6.4 \%)$ & $2.59 \%$ & $0.0 \%$ & $0 / 77(0.0 \%)$ & $0 / 76(0.0 \%)$ \\
\hline Médio purus & $330 / 2.950$ (11.2\%) & $0 \%$ & $0.0 \%$ & $0 / 20(0.0 \%)$ & $0 / 20(0.0 \%)$ \\
\hline Vale do javari & $1.147 / 2.563(44.7 \%)$ & $6.10 \%$ & $0.17 \%$ & $3 / 70(4.29 \%)$ & $1 / 70(1.43 \%)$ \\
\hline Total & $38.799 / 83.311(46.6 \%)$ & $594 / 38.799$ (1.53\%) & $41 / 38.799(0.11 \%)$ & $44 / 3.650$ (1.29\%) & $3 / 3.650(0.09 \%)$ \\
\hline
\end{tabular}

